\title{
Trinitrophenylation of Akazara Scallop Striated Adductor Myosin
}

\author{
Takao Ojima,* Keiki Yokomoto,* and Kiyoyoshi Nishita* \\ (Received September 29, 1988)
}

\begin{abstract}
When akazara scallop striated adductor myosin reacted with 2,4,6-trinitrobenzenesulfonate, one mol of trinitrophenyl(TNP)-group was rapidly incorporated into one mol of myosin. The amount of the TNP-group incorporated in the myosin was not influenced by the presence of $2 \mathrm{~mm}$ sodium pyrophosphate (PPi), however, the effects of trinitrophenylation on myosin ATPase activities were remarkably affected by the presence of PPi. Thus, the Ca-ATPase activity was decreased by trinitrophenylation to $80 \%$ of its original in the absence of $\mathrm{PPi}$, but to $40 \%$ in the presence of PPi. The Mg-ATPase activity both in the presence and absence of $\mathrm{Ca}^{2+}$ was increased

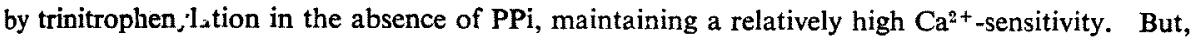
in the presence of PPi the activity in the absence of $\mathrm{Ca}^{2+}$ was significantly increased and that in the presence of $\mathrm{Ca}^{2+}$ was slightly decreased, losing its $\mathrm{Ca}^{2+}$-sensitivity.

Both tive decreased ATPase acti-ity and $\mathrm{Ca}^{2+}$-sensitivity of TNP-myosin were found to recover by the subsequent dithiothreitol (DTT)-treatment of the myosin. Moreover, the reactivity of the $\mathrm{SH}_{1}$-type thiol of the myosin with $\mathrm{N}$-(iodoacetyl)- $\mathrm{N}^{\prime}$-(5-sulfo-1-naphthyl)-ethylenediamine was found to be remarkably lowered by trinitrophenylation in the presence of PPi but recovered by the DTT-treatment, indicating that trinitrophenylation blocked the SH-group(s) of myosin.

From these results, it is concluded that the trir.itrophenylation of akazara scallop myosin, especially in the presence of PPi, is accompanied by the modification of the SH-group(s) and that the modification of SH-group causes a decrease not only in myosin ATPase activity but also in $\mathrm{Ca}^{2+}$-regulating ability.
\end{abstract}

Contraction of the molluscan muscle is regulated by myosin-linked regulatory light chains, ${ }^{1-3}$ ) although the troponin-tropomyosin system is additionally present on the actin filaments. ${ }^{4-7)}$ The myosin-linked regulation mechanism had been considered to act as a result of the inhibition of interaction between myosin and actin depending on the $\mathrm{Ca}^{2+}$ concentration, similar to the actinlinked tropomyosin-troponin system. ${ }^{1-3}$ However, it became evident that $\mathrm{Mg}$-ATPase activity of myosin from clam, ${ }^{8}$ akazara scallop, ${ }^{8-11}$ ) squid and ezo-giant scallop ${ }^{12)}$ showed $\mathrm{Ca}^{2+}$-sensitivity even in the absence of actin. Thus it has been proposed that the primary role of the reulatory light chain may not be to regulate the myosinactin interaction-site but rather to regulate the ATPase active-site. Hence, it becomes important to obtain structural information around the activesite in order to understand the mechanism of molluscan myosin-linked $\mathrm{Ca}^{2+}$-regulation.

In 1960 , Kubo et al. ${ }^{13)}$ attempted to determine the chemical structure of the ATPase active-site of rabbit skeletal myosin using 2,4,6-trinitrobenezenesulfonate (TNBS) as a modifying reagent, and showed that two lysine $\varepsilon$-amino groups per one mol of myosin which were intimately related to the ATPase activity were specifically modified. Furthermore, Mühlrad et al. ${ }^{14)}$ showed by trinitrophenylation that one ATPase active-site is present in each of the two heads of rabbit myosin. On the other hand, Miyanishi et al. ${ }^{15)}$ found that the amount of TNBS which reacted rapidly with rabbit myosin was different depending on the presence and absence of PPi, and proposed that the chemical structures of the two heads of myosin were different with each other. Recently, Kodama et al. ${ }^{10)}$ reported that when TNP-rabbit myosin was treated with DTT, the absorbance at $345 \mathrm{~nm}$ was decreased making it seem as if the TNP-groups bound to the myosin were removed. This was accompanied by the restoration of the inhibited Ca-ATPase and EDTA-ATPase ac-

* Laboratory of Biopolymer Chemistry, Faculty of Fisheries, Hokkaido University, Hakodate 041, Japan （星島孝男, 横本敬紀, 西田清義：北海道大学水産学部水産高分子化学讙座）.

Abbreviations: PPi, sodium pyrophosphate; TNP, trinitrophenyl; DTT, dithiothreitol; EGTA, ethyleneglycol-bis ( $\beta$-aminoethylether)-N, $\mathbf{N}^{\prime}$-tetraacetate; DPCC, diphenylcarbamyl chloride; HMM, heavy meromyosin; $\mathrm{S} 1$, subfragment-1; 1,5-IAEDANS, $\mathrm{N}$-(iodoacetyl)- $\mathrm{N}^{\prime}$-(5-sulfo-1-naphthyl)ethylenediamine. 
tivities. ${ }^{16)}$

In the present paper, we report the effects of trinitrophenylation and successive treatment with DTT, and 1,5-IAEDANS on the biochemical properties of akazara scallop myosin.

\section{Materials and Methods}

Myosins from striated adductor muscles of akazara scallop and rabbit skeletal muscles were prepared by the method of Nishita et $a l^{3}{ }^{3}$ and Perry, ${ }^{173}$ respectively. Trinitrophenylation of myosin was carried out in accordance with the method of Miyanishi et al. ${ }^{15)}$ as follows; myosin $(4-5 \mathrm{mg} / \mathrm{ml})$ in $0.5 \mathrm{M} \mathrm{KCl}, 0.1 \mathrm{M}$ imidazole- $\mathrm{HCl}$ (pH 7.0), $2 \mathrm{~mm} \mathrm{MgCl}_{2}$, and $0.1 \mathrm{~mm}$ EDTA was allowed to react with $0.25 \mathrm{~mm}$ TNBS in the presence and absence of $2 \mathrm{mM} \mathrm{PPi}$ at $15^{\circ} \mathrm{C}$. At various intervals, aliquots were taken out and diluted with 10 volumes of cold $2 \mathrm{mM} \mathrm{MgCl}_{2}$ to stop the reaction. The formed precipitates were collected by centrifugation at $10,000 \times \mathrm{g}$ for 10 min, resuspended in $0.04 \mathrm{M} \mathrm{KCl}$ and $2 \mathrm{mM} \mathrm{MgCl}_{2}$. The precipitates were spun down, and dissolved in and dialyzed against $0.6 \mathrm{M} \mathrm{KCl}$ and $20 \mathrm{~mm}$ imidazole- $\mathrm{HCl}(\mathrm{pH} 7.0)$. Trinitrophenylation proceeded insignificantly during these procedures. The number of bound TNP-groups was calculated using a molar extinction coefficient of TNP-lysine as $1.45 \times 10^{4}{ }^{18}$ ) and the molecular weight of myosin as $4.8 \times 10^{5} .{ }^{18}$ ) The difference absorption spectrum of TNP-myosin was scanned by using a Hitachi UV 200-10 spectrophotometer. EDTAand $\mathrm{Ca}$-ATPase activities of myosin were measured at $15^{\circ} \mathrm{C}$ in a medium containing $0.6 \mathrm{M} \mathrm{KCl}, 25 \mathrm{~mm}$ Tris maleate (pH 7.0), $1 \mathrm{~mm}$ ATP, and $5 \mathrm{~mm}$ EDTA and $5 \mathrm{~mm} \mathrm{CaCl}$, respectively. Mg-ATPase activity of myosin and actomyosin was measured at $15^{\circ} \mathrm{C}$ in a medium containing $0.03 \mathrm{M} \mathrm{KCl}, 20$ $\mathrm{mm}$ Tris maleate ( $\mathrm{pH} 6.8$ ), $2 \mathrm{mM} \mathrm{MgCl}_{2}, 1 \mathrm{~mm}$ ATP and $0.2 \mathrm{mM}$ EGTA (in the absence of $\mathrm{Ca}^{2+}$ ) and $0.2 \mathrm{mM}$ EGTA plus $0.3 \mathrm{mM} \mathrm{CaCl}$ (in the presence of $\mathrm{Ca}^{2+}$ ). The inorganic phosphate liberated by ATP hydrolysis was determined according to the method of Youngburg and Youngburg. ${ }^{20)}$ The $\mathrm{Ca}^{2+}$-binding of myosin was measured by the equilibrium dialysis method. ${ }^{21,22)}$ Akazara scallop myosin S1 was prepared according to the method of Weeds and Taylor ${ }^{23}$ with a slight modification as follows; akazara scallop myosin $(10 \mathrm{mg} / \mathrm{ml})$ in $0.12 \mathrm{M} \mathrm{KCl}, 20 \mathrm{mM}$ imidazole- $\mathrm{HCl}(\mathrm{pH} \mathrm{7.0}), 1 \mathrm{mM}$ EDTA and $5 \mathrm{~mm} 2-$ mercaptoethanol was digested with $0.05 \mathrm{mg} / \mathrm{ml}$ $\alpha$-chymotrypsin at $15^{\circ} \mathrm{C}$ for $30 \mathrm{~min}$. The digestion was stopped by the addition of $0.2 \mathrm{mM}$ phenylmethylsulfonylfluoride. After dialyzing against $30 \mathrm{mM} \mathrm{KCl}$ and $20 \mathrm{~mm}$ imidazole- $\mathrm{HCl}$ (pH 7.0 ), the digests were centrifuged at $100,000 \times \mathrm{g}$ for $30 \mathrm{~min}$ to remove the insoluble materials, then solid ammonium sulfate was added to the $60 \%$ saturation. The thus formed S1 precipitates were collected by centrifugation at $10,000 \times \mathrm{g}$ for $15 \mathrm{~min}$, and dialyzed against $30 \mathrm{~mm} \mathrm{KCl}$ and $20 \mathrm{~mm}$ imidazole- $\mathrm{HCl}$ (pH 7.0). The dialyzates were purified by gel filtration on a Sephacryl S-300 column $(2.5 \times 75 \mathrm{~cm})$ preequilibrated with the above dialysis buffer. The reaction of $\mathrm{S} 1$ and trinitrophenylated S1 with 1,5-IAEDANS was carried out according to the method of Hozumi and Mühlrad $^{24)} ; 1$,5-IAEDANS $(20 \mu \mathrm{M})$ was added to $\mathrm{S} 1(20 \mu \mathrm{M})$ in $30 \mathrm{mM} \mathrm{KCl}, 20 \mathrm{~mm}$ imidazole- $\mathrm{HCl}$ (pH 7.0) and $1 \mathrm{~mm} \mathrm{MgATP}$ and was allowed to react at $0^{\circ} \mathrm{C}$ for $12 \mathrm{~h}$. The reaction was stopped by the addition of $5 \mathrm{~mm} 2$ mercaptoethanol. The mixture was dialyzed against $30 \mathrm{mM} \mathrm{KCl}, 20 \mathrm{mM}$ imidazole- $\mathrm{HCl}(\mathrm{pH}$ 7.0 ) and $5 \mathrm{~mm} 2$-mercaptoethanol to remove unreacted 1,5-IAEDANS. Tryptic digestion of akazara scallop S1 was carried out essentially by the method of Yamamoto and Sekine. ${ }^{25)}$ Thus, $\mathrm{S} 1(2 \mathrm{mg} / \mathrm{m} /)$ in $30 \mathrm{~mm} \mathrm{KCl}, 20 \mathrm{~mm}$ imidazole-HCl (pH 7.0) and $5 \mathrm{~mm}$ 2-mercaptoethanol was digested with the 1/50 weight of DPCC-treated trypsin (Sigma Chem. Co.). At various intervals, $0.08 \mathrm{ml}$ of the reaction mixture was taken out and mixed with an equal volume of $10 \mathrm{M}$ urea, $1 \%$ SDS, $50 \mathrm{~mm}$ Tris- $\mathrm{HCl}$ ( $\mathrm{pH} \mathrm{8.9),} \mathrm{0.02 \%} \mathrm{bromo-}$ phenolblue and $0.6 \mathrm{M}$ 2-mercaptoethanol. The mixture was then heated at $80-100^{\circ} \mathrm{C}$ for $2 \mathrm{~min}$, and subjected to SDS-polyacrylamide gel electrophoresis. ${ }^{26)}$ AEDANS-peptide fragments in the gel were detected under long wave UV-light (340 $\mathrm{nm}$ ). Urea-polyacrylamide gel electrophoresis was carried out according to the method of Perrie and Perry. ${ }^{27)}$ Protein concentration was determined by the biuret method ${ }^{28)}$ using bovine serum albumin fraction $V$ as a standard protein.

\section{Results}

\section{Trinitrophenylation of Myosin}

As shown in Fig. $1 \mathrm{~A}$ and $\mathrm{B}$, the reaction of akazara scallop and rabbit myosins with TNBS proceeded biphasically, i.e., an initial rapid phase and a latter slow phase. As can be seen in Fig. $1 B$, the number of rapidly incorporated TNP. 

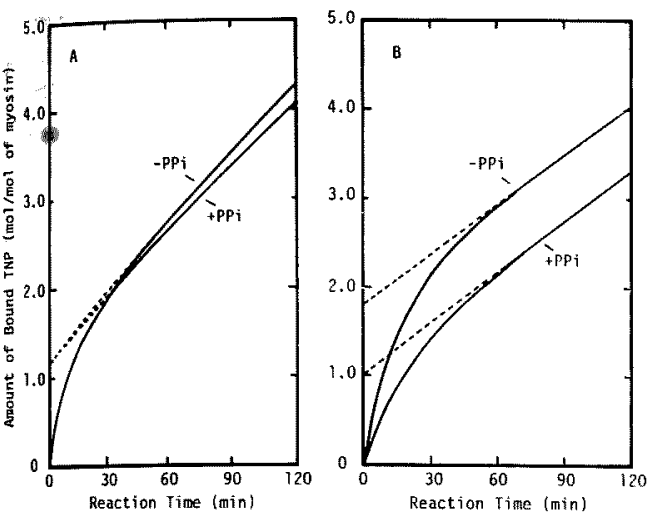

Fig. 1. Trinitrophenylation of akazara scallop and rabbit myosin with 2,4,6-trinitrobenezenesulfonate (TNBS). Akazara scallop myosin (A) and rabbit myosin (B) $(4 \mathrm{mg} / \mathrm{ml})$ were allowed to react with $0.25 \mathrm{mM}$ TNBS at $15^{\circ} \mathrm{C}$ in $0.5 \mathrm{M} \mathrm{KCl}$, $0.1 \mathrm{M}$ imidazole- $\mathrm{HCl}$ (pH 7.0), $2 \mathrm{~mm} \mathrm{MgCl}_{2}$, $0.1 \mathrm{~mm}$ EDTA, and either in the presence or absence of $2 \mathrm{~mm}$ PPi (+PPi and $-\mathrm{PPi}$, respectively). The amount of trinitrophenyl (TNP)groups bound was estimated from the absorbance at $34.5 \mathrm{~nm} .^{18)}$

groups into rabbit myosin was determined by the extrapolation of the latter slope as $1 \mathrm{~mol}$ and 2 $\mathrm{mol} / \mathrm{mol}$ myosin in the presence and absence of $\mathrm{PPi}$, respectively, in accord with the results of Miyanishi et al. ${ }^{15)}$ However, the TNP-group incorporated into akazara myosin was $1 \mathrm{~mol} / \mathrm{mol}$ myosin regardless of the presence or absence of PPi (Fig. 1A).

\section{Difference Absorption Spectrum of TNP-Myosin}

Mühlrad ${ }^{2 \theta}$ ) reported that the UV-absorption spectrum of TNP-group bound to rabbit skeletal myosin (and its HMM and S1) blue-shifted by the addition of ADP or PPi, suggesting that the environment of the functional lysine residue becomes less polar upon binding of ATP analogue to myosin, i.e., it becomes buried in the hydrophobic core of the molecule. Then, the effect of PPi on the UV-absorption spectrum of the TNP-group attached to the akazara scallop myosin was studied. As shown in Fig. 2A, akazara scallop myosins which trinitrophenylated in the presence and absence of PPi were both incapable of showing a difference spectrum by the addition of PPi. On the other hand, rabbit myosin trinitrophenylated in the absence of PPi showed a difference spectrum upon the addition of PPi, while, that modified in the absence of PPi did not (Fig. 2B).

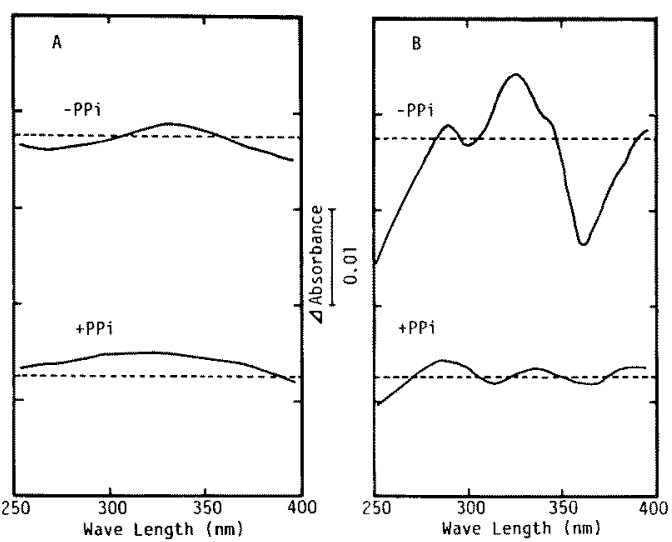

Fig. 2. Difference spectra of TNP-myosin induced by the addition of PPi. Difference spectra of TNP-myosin $(2.5 \mathrm{mg} / \mathrm{ml})$ prepared by the trinitrophenylation in the presence $(+\mathrm{PPi})$ or absence (-PPi) of $2 \mathrm{~mm} \mathrm{PPi}$ were induced by the addition of $1 \mathrm{mM} \mathrm{PPi}$ in $0.6 \mathrm{M} \mathrm{KCl}, 20 \mathrm{~mm}$ Tris- $\mathrm{HCl}$ ( $\mathrm{pH} 7.5$ ), and $2 \mathrm{~mm} \mathrm{MgCl}_{2}$. A) akazara scallop TNP-myosin. B) rabbit skeletal TNPmyosin. Dotted lines indicate the base lines.


Fig. 3. Effect of trinitrophenylation on the EDTAATPase activities of akazara scallop and rabbit myosin. Akazara scallop and rabbit myosin were reacted with TNBS in the presence $(-)$ or absence ( $O$ ) of $2 \mathrm{~mm} \mathrm{PPi}$ for various times indicated on the abscissa as described in the text. The EDTA-ATPase activities of akazara scallop (A) and rabbit (B) TNP-myosins were assayed at $15^{\circ} \mathrm{C}$ in a medium containing $0.6 \mathrm{M} \mathrm{KCl}, 5 \mathrm{~mm}$ EDTA, $25 \mathrm{~mm}$ Tris maleate (pH 7.0), and $1 \mathrm{~mm}$ ATP.

Effect of Trinitrophenylation on EDTA- and $\mathrm{Ca}$ ATPase Activities

Figs. 3 and 4 show the changes in EDTA- and Ca-ATPase activities of akazara scallop and rabbit myosins during the trinitrophenylation.

The EDTA-ATPase activity of akazara scallop 

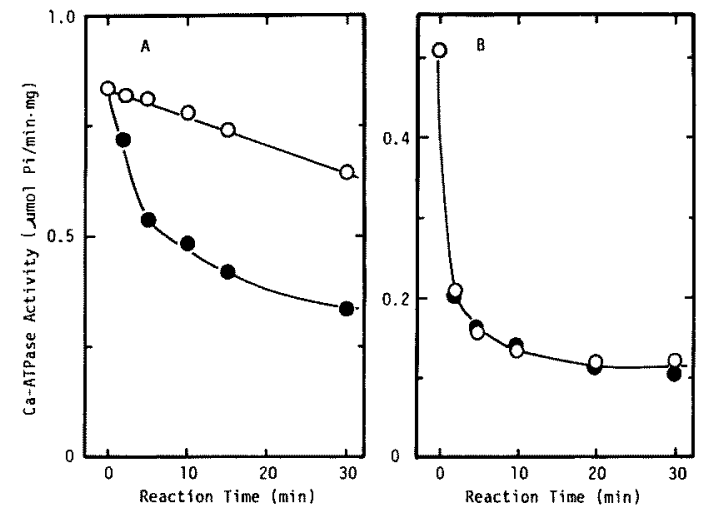

Fig. 4. Effect of trinitrophenylation on the $\mathrm{Ca}$ ATPase activities of akazara scallop and rabbit myosin. The myosins were reacted with TNBS in the presence (O) and absence (O) of $2 \mathrm{~mm}$ $\mathrm{PPi}$ for various times indicated on the abscissa as described in the text. The Ca-ATPase activity of akazara scallop TNP-myosin (A) and rabbit TNP-myosin (B) was assayed as in Fig. 3 except that $5 \mathrm{mM} \mathrm{CaCl}_{2}$ was present in the reaction mixture instead of $5 \mathrm{~mm}$ EDTA.

myosin was repressed by trinitrophenylation depending on the presence or absence of PPi, i.e., it was repressed to about $30 \%$ of its original in the absence of PPi and less than $5 \%$ in its presence. On the other hand, the EDTA-ATPase activity of rabbit myosin was repressed to about $5 \%$ irrespective of the presence or absence of PPi (Fig. 3B).

The decrease in Ca-ATPase activity of akazara scallop myosin during trinitrophenylation was also affected by the presence of PPi, i.e., the activity of akazara scallop myosin modified in the absence of $\mathrm{PPi}$ was repressed to only $80 \%$ of its original but that modified in the presence of $\mathrm{PPi}$ was repressed to about $40 \%$ (Fig. 4A). The activity of rabbit myosin was repressed to about $30 \%$ regardless of the presence or absence of PPi (Fig. 4B).

Effect of Trinitrophenylation on $\mathrm{Ca}^{2+}-$ Sensitivity of Myosin Mg-ATPase Activity

Since molluscan myosin has $\mathrm{Ca}^{2+}$-dependent Mg-ATPase activity unlike the vertebrate striated muscle myosin, ${ }^{8-12)}$ we examined the effect of trinitrophenylation on myosin Mg-ATPase activity and its $\mathrm{Ca}^{2+}$-sensitivity.

As shown in Fig. 5A, when akazara scallop myosin was modified in the absence of PPi, the Mg-ATPase activity both in the presence and absence of $\mathrm{Ca}^{2+}$ increased as the modification



Fig. 5. Effect of trinitrophenylation on the $\mathrm{Mg}$ ATPase activities of akazara scallop and rabbit myosin. The Mg-ATPase activities of akazara scallop (A) and rabbit (B) TNP-myosins which were obtained by reacting with TNBS for various times indicated on the abscissa either in the absence $(O)$ or presence $(\bullet)$ of $2 \mathrm{mM} \mathrm{PPi}$ were measured at $15^{\circ} \mathrm{C}$ in a medium containing $30 \mathrm{~mm}$ $\mathrm{KCl}, 20 \mathrm{mM}$ Tris maleate (pH 6.8), $2 \mathrm{mM} \mathrm{MgCl}_{2}$, and $1 \mathrm{~mm}$ ATP. The activity of akazara scallop TNP-myosin was assayed either in the presence (-) or absence (--) of $0.1 \mathrm{mM} \mathrm{Ca}^{2+}$. The ureagel electrophoretic patterns of akazara scallop untreated myosin (CM) and akazara scallop TNP-myosin modified in the presence of $2 \mathrm{~mm}$ PPi for $30 \mathrm{~min}$ (TNP-M $(+\mathrm{PPi})$ ) are shown in inset of the figure. RLC and SHLC were regulatory and sulfhydryl light chains of myosin. respectively.

proceeded showing a slight decrease in $\mathrm{Ca}^{2+}$ sensitivity. On the other hand, when the myosin was modified in the presence of $\mathrm{PPi}$, the $\mathrm{Mg}$ ATPase activity in the presence of $\mathrm{Ca}^{2+}$ decreased slightly but that in the absence of $\mathrm{Ca}^{2+}$ significantly increased, resulting in a decrease in $\mathrm{Ca}^{2+}$-sensitivity. This decrease in $\mathrm{Ca}^{2+}$-sensitivity war shown not to be due to the dissociation of regula tory light chain (Fig. 5A, inset).

On the other hand, Mg-ATPase activity of rabbit myosin was increased markedly by the modification in the absence of PPi but slightly ir its presence (Fig. 5B).

\section{Effect of Trinitrophenylation on the $\mathrm{Ca}^{2+}$-Binding of Akazara Scallop Myosin}

It has been proved that the $\mathrm{Ca}^{2+}$-binding of myosin is involved in the $\mathrm{Ca}^{2+}$-regulation of the molluscan myosin..$^{1,2,12,30)}$ Recently, Kishimura et al. ${ }^{22)}$ reported that $1 \mathrm{~mol}$ of akazara scallop myosin bound $2 \mathrm{~mol}$ of $\mathrm{Ca}^{2+}$ but its desensitized myosin, having had their regulatory light chains 
completely removed, bound no $\mathrm{Ca}^{2+}$. In order to investigate the cause for the decrease in $\mathrm{Ca}^{2+}$ sensitivity during trinitrophenylation, the $\mathrm{Ca}^{2+}$ binding of unmodified and modified akazara scallop myosins was measured by the equilibrium dialysis method using ${ }^{45} \mathrm{Ca}$. Fig. 6 shows that the myosins modified in the presence and absence of PPi could bind about $1.2-1.7 \mathrm{~mol} \mathrm{Ca}{ }^{2+} / \mathrm{mol}$ myosin at $10^{-4} \mathrm{M} \mathrm{Ca}^{2+}$, indicating that the decrease in $\mathrm{Ca}^{2+}$-sensitivity was not due to the alteration of its $\mathrm{Ca}^{2+}$-binding ability.

\section{Recovery of ATPase Activities and $\mathrm{Ca}^{2+}-$ Sensitivity by DTT-Treatment of TNP-Myosin}

It has already been reported that when TNPrabbit myosin was treated with DTT, its absorbance at $345 \mathrm{~nm}$ was decreased. ${ }^{16)}$ Therefore, we examined the effects of DTT-treatment on the $\mathrm{Mg}$-ATPase activities and $\mathrm{Ca}^{2+}$-sensitivity of TNP-akazara scallop myosin modified in the presence of $2 \mathrm{mM} \mathrm{PPi}$. The TNP-myosin was dialyzed against $0.6 \mathrm{M} \mathrm{KCl}, 20 \mathrm{~mm}$ imidazole- $\mathrm{HCl}$ $(\mathrm{pH} \mathrm{7.0)}$ and $1 \mathrm{mM} \mathrm{DTT}$, and then aliquots were taken at various times to measure the $\mathrm{Mg}$ - and EDTA-ATPase activities and to determine the number of bound TNP-group. As seen in Fig. 7A, the $\mathrm{Mg}$-ATPase activities and also $\mathrm{Ca}^{2+}$-sensitivity which had decreased by the trinitrophenylation

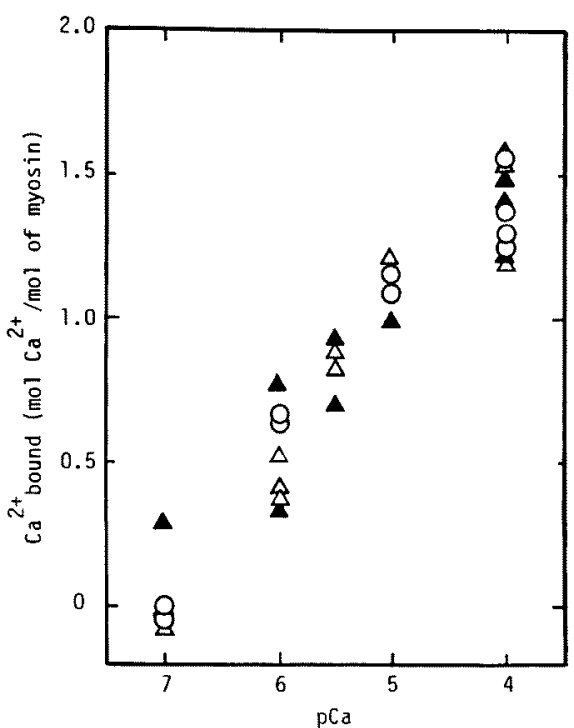

Fig. 6. $\mathrm{Ca}^{2+}$-binding of akazara scallop TNPmyosin. $\mathrm{Ca}^{2+}$-binding of akazara untreated myosin (O), TNP-myosins modified in the absence $(\triangle)$ and presence $(\Delta)$ of $2 \mathrm{~mm}$ PPi were measured at $10^{\circ} \mathrm{C}$ by the equilibrium dialysis method using ${ }^{45} \mathrm{Ca}$ in the medium of $0.5 \mathrm{M} \mathrm{KCl}, 20 \mathrm{~mm}$ Tris maleate ( $\mathrm{pH} 6.8$ ), and $5 \mathrm{mg} / \mathrm{m} /$ myosin. Free $\mathrm{Ca}^{2+}$ concentration was determined by using Ca-EGTA buffer adopting the apparent association constant $8.45 \times 10^{5} \mathrm{M}^{-1}{ }^{33}$


Fig. 7. Effect of dithiothreitol (DTT)-treatment on the Mg- and EDTA-ATPase activities of akazara scallop TNP-myosin. TNP-myosin was prepared by trinitrophenylation of akazara scallop myosin in the presence of $2 \mathrm{~mm}$ PPi for $30 \mathrm{~min}$. The TNP-myosin was dialyzed against $0.6 \mathrm{M} \mathrm{KCl}, 20 \mathrm{~mm}$ imidazole- $\mathrm{HCl}(\mathrm{pH} 7.0), 1 \mathrm{~mm}$ DTT for various times, then diluted to $60 \mathrm{mM} \mathrm{KCl}$ and collected by centrifugation $(10,000 \times \mathrm{g}$, for $10 \mathrm{~min})$. The DTT-treated TNP-myosin was dissolved in $0.6 \mathrm{M} \mathrm{KCl}, 20 \mathrm{~mm}$ imidazole- $\mathrm{HCl}(\mathrm{pH} 7.0)$ and used for ATPase assay and bound TNP determination. Amount of bound TNP $(\triangle)$ was expressed by mol of TNP-group/mol of myosin. The Mg-ATPase activities in the presence $(\bullet)$ and absence $(0)$ of $0.1 \mathrm{mM} \mathrm{Ca}{ }^{2+}$ were measured under the same conditions as in Fig. 5. $\mathrm{Ca}^{2+}$-sensitivity of the $\mathrm{Mg}-\mathrm{ATPase}$ activity $(x)$ was calculated by the following equation:

$$
\mathrm{Ca}^{2+} \text {-sensitivity }=\left[1-\frac{\text { Activity }\left(-\mathrm{Ca}^{2+}\right)}{\text { Activity }\left(+\mathrm{Ca}^{2+}\right)}\right] \times 100(\%)
$$

EDTA-ATPase activity $(\square)$ was measured as in Fig. 3. Co, activities of untreated myosin. 


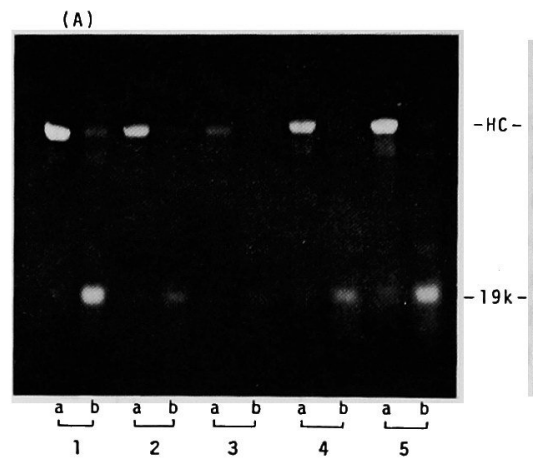

(B)

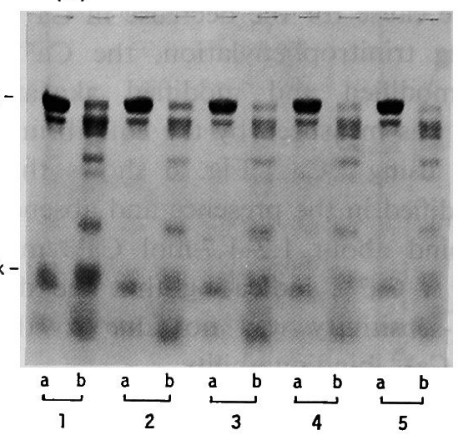

Fig. 8. SDS-gel electrophoresis of AEDANS-labeled TNP-S1 and DTT-treated TNP-S1. Trinitrophenylation and DTT-treatment of akazara scallop S1 was carried out as described in Table 1. Control S1 (untreated S1), TNP-S1s, and DTT-treated TNP-S1s were incubated at $0^{\circ} \mathrm{C}$ overnight with equimolar amount of 1,5-IAEDANS in $30 \mathrm{~mm} \mathrm{KCl,} 20 \mathrm{~mm}$ imidazole$\mathrm{HCl}(\mathrm{pH} \mathrm{7.0)}$. The AEDANS-labeled S1s (a) and those digested by trypsin (b) were analyzed by SDS-gel electrophoresis according to the method of Porzio and Pearson. ${ }^{26)}$ Photographs of the gel were taken under UV illumination (A) or after staining with Coomassie Brilliant Blue (B). 1, control S1; 2, TNP-S1 (-PPi); 3, TNP-S1 (+PPi); 4, DTT-treated TNP-S1 (-PPi); 5, DTT-treated TNP-S1 (+PPi). About $80 \mu \mathrm{g}$ of sample was applied to each well.

recovered rapidly by the DTT-treatment. In this case, about $0.2 \mathrm{~mol}$ TNP-group/mol myosin was released in $3 \mathrm{~h}$ of DTT-treatment, and about 0.5 mol TNP-group/mol myosin (from $1.2 \mathrm{~mol}$ to $0.7 \mathrm{~mol}$ TNP-group $/ \mathrm{mol}$ myosin) was released in $12 \mathrm{~h}$. This was accompanied by the recovery of EDTA-ATPase activity as well as the $\mathrm{Ca}^{2+}$ sensitivity of Mg-ATPase activity (Fig. 7B).

\section{Reaction of TNP-Akazara Scallop Myosin with 1, 5-IAEDANS}

In order to investigate whether the trinitrophenylation and the DTT-treatment of akazara scallop myosin affect reversibly on the reactivity of SH-group(s) similar to $\mathrm{SH}_{1}$ of vertebrate skeletal myosin which is known to be essential for ATPase activity, the reactivity of TNP-S1 with 1,5IAEDANS, a fluorescent reagent, was examined before and after the DTT-treatment. In this experiment, we used S1 instead of intact myosin since the modified site can be followed more readily. After the reaction with 1,5-IAEDANS, the modified S1 was digested with trypsin and subjected to SDS-polyacrylamide gel electrophoresis. Upon exposing the electrophoretogram to ultraviolet light, its fluorescence was observed on the $19 \mathrm{kDa}$ band alone, suggesting that reactive $\mathrm{SH}$-groups analogous to rabbit myosin $\mathrm{SH}_{1}$, which is known to locate in the $20 \mathrm{kDa}$ fragment region of rabbit S1, was modified with 1,5-IAEDANS (Fig. 8). Whereas the $19 \mathrm{kDa}$ fragment from akazara scallop S1 trinitrophenylated in the absence and presence of PPi showed weak and practically no fluorescence, respectively, suggesting that reactivity of the SH-group(s) decreased by trinitrophenylation especially in the presence of PPi. Moreover, it became evident that DTTtreatment of the TNP-S1 enabled its $19 \mathrm{kDa}$

Table 1. Effect of dithiothreitol (DTT)-treatment on the EDTA-ATPase activity of akazara scallop TNP-S1. Akazara scallop S1 $(3 \mathrm{mg} / \mathrm{m} l)$ was reacted at $15^{\circ} \mathrm{C}$ with $0.25 \mathrm{~mm}$ TNBS for $30 \mathrm{~min}$ in a solution containing $0.5 \mathrm{M} \mathrm{KCl}, 0.1 \mathrm{M}$ imidazole- $\mathrm{HCl} \quad(\mathrm{pH} 7.0), 2 \mathrm{mM} \quad \mathrm{MgCl}_{2}, \quad 0.1 \mathrm{~mm}$ EDTA, and either iu the resence or absence of $2 \mathrm{mM} P P i$ ( $-\mathrm{PPi}$ and $+\mathrm{PPi}$, respectively), and dialyzed against $30 \mathrm{~mm} \mathrm{KCl,} 20 \mathrm{~mm}$ imidazole$\mathrm{HCl}$ (pH 7.0). The TNP-S1 (-PPi) and TNP-S1 (+PPi) were then dialyzed against $30 \mathrm{~mm}$ $\mathrm{KCl}, 20 \mathrm{~mm}$ imidazole- $\mathrm{HCl}(\mathrm{pH} 7.0)$ containing $1 \mathrm{~mm}$ DTT for $12 \mathrm{~h}$. The DTT-treated TNPSls were dialyzed against the same buffer without DTT, and their EDTA-ATPase activities were measured under the same condition as described in the legend for Fig. 3

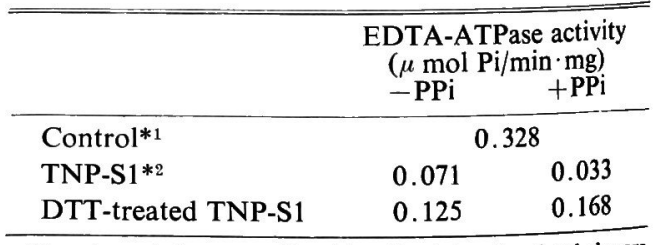

*1 untreated akazara scallop S1, *2 trinitrophenylated akazara scallop S1. 
fragment region to react with 1,5-IAEDANS. In addition, the alteration of the EDTA-ATPase activity was accompanied by an alteration in the reactivity of SH-group(s) (Table 1).

\section{Discussion}

In order to obtain information concerning the chemical structure of the molluscan $\mathrm{Ca}^{2+}$-regulatory myosin, akazara scallop striated adductor myosin was reacted with TNBS, DTT and 1,5IAEDANS successively, and their effects on ATPase activities, $\mathrm{Ca}^{2+}$-sensitivity and tryptic fragmentation were investigated.

Akazara scallop myosin was shown to possess $1 \mathrm{~mol}$ of reactive residue per mol of myosin which can be readily trinitrophenylated. The TNPgroup attached to akazara scallop myosin was found to be incapable of showing the difference spectrum upon addition of $\mathrm{PPi}$, suggesting that its environment was not altered by the addition of $\mathrm{PPi}$. These properties were similar to those reported in porcine cardiac and chicken gizzard myosins, i.e., these myosins were shown to incorporate only $1 \mathrm{~mol}$ of the TNP-group rapidly, and the TNP-groups were incapable of showing the difference spectrum. ${ }^{31}$ Srivastava et al. ${ }^{31}$ proposed that the reactive lysine residue only in head Bs of cardiac and gizzard myosins, that catalyzing the initial burst of inorganic phosphate liberation, was trinitrophenylated regardless of the presence or absence of PPi, thus the difference spectrum was not observed.

On the contrary, rabbit skeletal myosin was reported to have $2 \mathrm{~mol}$ and $1 \mathrm{~mol}$ of lysine residue per mol of myosin that can be specifically trinitrophenylated in the absence and presence of PPi, 1espectively, ${ }^{15)}$ and the TNP-group attached to reactive lysine residue showed a considerable blue shift in its absorption spectrum by the addition of PPi, suggesting that the environment of the reactive lysine residue becomes buried in the hydrophobic core of the molecule. ${ }^{2 \theta)}$ The spectral change was interpreted to occur from the TNPgroup attached to the non-burst head (head A) of the two TNP-heads by the addition of ADP or $\mathrm{PPi}_{1}{ }^{\text {ss) }}$ Consequently, rabbit myosin was interpreted to have two equimolar kinds of head with a reactive lysine residue but the residues behave differentely to trinitrophenylation because of the difference in the two heads' chemical structures. ${ }^{15}$ ) It was therefore assumed that only one of the two heads of akazara scallop myosin has an reac- tive residue, i.e., the chemical structures of the two heads are different based on the previous interpretation. ${ }^{15,31)}$

Both EDTA- and Ca-ATPase activities and $\mathrm{Ca}^{2+}$-sensitivity of myosin were decreased by the trinitrophenylation depending on the presence of PPi (Figs. 3-5). However, the decreased activities were recovered when the TNP-myosin was treated with DTT (Fig. 7). Generally, it is hardly explicable that the TNP-group attached to lysine residue can be removed by the DTT-treatment. Moreover, the Mg- and EDTA-ATPase activities of the TNP-myosin were restored by the DTTtreatment, but was not necessarily stoichiometric with the amount of TNP-group removed (Fig. 7). We therefore assumed that $\mathrm{SH}$-modification might occur in akazara scallop myosin depending on the presence of PPi during trinitrophenylation, and that such a modification could be readily reversed by the DTT-treatment. Recently, Nakata et al. ${ }^{32)}$ found that nitrite production occurred when chicken breast and porcine cardiac myosins were trinitrophenylated and subsequently allowed to stand at $20^{\circ} \mathrm{C}$ in an alkaline $\mathrm{pH}$, but did not occur when the SH-group had been blocked with 2nitro-5-thiocyanobenzoate. From these findings, they proposed that the TNP-group bound to the reactive lysine residue might react with $\mathrm{SH}_{1}$.

Thus using the modification with 1,5-IAEDANS, we examined whether or not the SH-group remained reactive even after the trinitrophenylation. As a result, the SH-group of TNP-akazara scallop myosin corresponding to rabbit myosin $\mathrm{SH}_{1}$ was found to hardly react with the fluorescent reagent. Moreover, the repressed reactivity was recovered after the subsequent DTT-treatment. These facts may indicate that the trinitrophenylation was accompanied by the oxidation of the SHgroup. We therefore consider that the difference in the effects of trinitrophenylation on the ATPase activities between akazara scallop and vertebrate skeletal myosins may be attributed to the difference in the subsequent $\mathrm{SH}$ modification by the trinitrophenyl group(s) attached to lysine residue.

As already stated, trinitrophenylation of akazara scallop myosin was associated with the decrease in $\mathrm{Ca}$ - and EDTA-ATPase activities and $\mathrm{Ca}^{2+}$ sensitivity of Mg-ATPase activity. It was shown that the decrease in $\mathrm{Ca}^{2+}$-sensitivity was not due to the dissociation of the regulatory light chains from myosin nor the decrease in $\mathrm{Ca}^{2+}$. binding ability of myosin. Therefore, the trinitrophenylation may directly cause the decrease in 
not only Ca- and EDTA-ATPase activities but also $\mathrm{Ca}^{2+}$-sensitivity. This suggests that the site involved in $\mathrm{Ca}^{2+}$-regulation may be close to the ATPase active-site or on the site communicating with the active-site for $\mathrm{Ca}^{2+}$-regulation.

\section{References}

1) J. Kendrick-Jones, W. Lehman, and A. G. SzentGyörgyi: J. Mol. Biol., 74, 179-203 (1970).

2) A. G. Szent-Györgyi, E. M. Szentkiralyi, and J. Kendrick-Jones: J. Mol. Biol., 104, 747-775 (1973).

3) K. Nishita, T. Ojima, and S. Watanabe: $J$. Biochem., 86, 663-673 (1979).

4) A. Goldberg and W. Lehman: Biochem. J., 171, 413-418 (1978).

5) K. Konno: J. Biochem., 84, 1431-1440 (1978).

6) T. Ojima and K. Nishita: J. Biochem., 100, 821824 (1986).

7) T. Ojima and K. Nishita: J. Biol. Chem., 261, 16749-16754 (1986).

8) G. Ashiba, T. Asáda, and S. Watanabe: $J$. Biochem., 88, 837-846 (1980).

9) T. Ojima, K. Nishita, and S. Watanabe: $J$. Biochem., 93, 607-613 (1983).

10) T. Ojima, K. Nishita, and S. Watanabe: $J$. Biochem., 89, 1333-1335 (1981).

11) T. Ojima, K. Nishita, and S. Watanabe: $J$. Biochem., 96, 1109-1115 (1984).

12) K. Konno, K. Arai, M. Yoshida, and $S$. Watanabe: J. Biochem., 89, 581-589 (1981).

13) S. Kubo, S. Tokura, and Y. Tonomura: $J$. Biol. Chem., 235, 2835-2839 (1960).

14) A. Mühlrad, R. Lamed, and A. Oplatka: J. Biol. Chem., 250, 175-181 (1975).

15) T. Miyanishi, A. Inoue, and Y. Tonomura: $J$. Biochem., 85, 747-753 (1979).

16) S. Kodama, K. Konno, K. Arai, and S.
Watanabe: J. Biochem., 97, 831-836 (1985).

17) S. V. Perry: in "Method in Enzymology" (a by S. P. Colowick, and N. O. Kaplan.) vol. Academic Press, New York, 1955, pp. 582-588.

18) T. Okuyama and K. Satake: J. Biochem., 4' 454-466 (1960).

19) Y. Tonomura: Muscle Proteins, Muscle Cor traction and Cation Transport, Japan Scientif Society Press, Tokyo, 1972, pp. 31-33.

20) G. E. Youngburg and M. N. Youngburg: . Lab. Clin. Med. 16, 158-166 (1930).

21) H. Kuwayama and K. Yagi: J. Biochem., 8: 1245-1255 (1979).

22) H. Kishimura, T. Ojima, and K. Nishita: Nippe Suisan Gakkaishi, 52, 1469-1472 (1986).

23) A. G. Weeds and R.S. Taylor: Nature, 25 54-56 (1975).

24) T. Hozumi and A. Mühlrad: Biochemistry, 2 2945-2950 (1981).

25) K. Yamamoto and T. Sekine: J. Biochem., 8 1855-1862 (1979).

26) M. A. Porzio and A. M. Pearson: Bioches Biophys. Acta, 490, 27-34 (1977).

27) W. T. Perrie and S. V. Perry: Biochem. J., 11 31-38 (1970).

28) A. G. Gornall, C. S. Bardawill, and M. M. Davi J. Biol. Chen., 177, 751-766 (1949).

29) A. Mühlrad: Biochim. Biophys. Acta, 493, 15 166 (1977).

30) P. D., Chantler and A. G. Szent-Györgyi: Mol. Biol., 138, 473-492 (1980).

31) S. K. Srivastava, Y. Tonomura, and A. Inou J. Biochem., 86, 725-731 (1979).

32) S. Nakata, T. Eiki, N. Tanaka, T. Koyama, 1 Tsukui, and S. Watanabe: J. Biochem., 99, 2 32 (1986).

33) H. Harafuji and Y. Ogawa: J. Biochem., 8 1305-1312 (1980). 